\title{
Improved green and sintered density of alumina parts fabricated by binder jetting and subsequent slurry infiltration
}

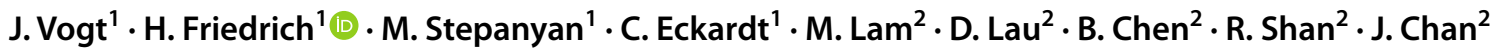

Received: 12 April 2021 / Accepted: 13 September 2021 / Published online: 7 December 2021

(C) The Author(s) 2021

\begin{abstract}
Additive Manufacturing (AM) of ceramics is a constantly emerging field of interest both in research and in industry. Binder jetting-based AM of ceramics in particular offers the opportunity to produce large ceramic parts with a high wall thickness at a high throughput. One limitation is that it requires flowable powders, which are generally coarse and thus exhibit only limited sintering activity. The resulting low sintered densities impede the commercial binder jetting-based production of dense oxide ceramics. We present an approach to efficiently increase the green density of binder jetted alumina parts by optimized slurry infiltration, which also leads to a significant increase in the sintered density. In a first step, alumina parts were fabricated via binder jetting, using a $20-\mu \mathrm{m}$-sized alumina powder, yielding relative green densities of about $47-49 \%$. Initial sintering studies with powder compacts showed that sintering even above $1900{ }^{\circ} \mathrm{C}$ is not sufficient to achieve acceptable densification. Therefore, green samples were infiltrated with a highly filled ceramic slurry to fill the remaining pores (about 2-5 $\mu \mathrm{m}$ in size) with smaller particles and thus increase the packing density. Particle volume content (40-50 vol\%), particle size (100-180 nm) and the infiltration procedure were adapted for tests on cuboid samples to achieve a high penetration of the green bodies and a high degree of pore filling. In this way, the relative green density could be increased starting from about $47 \%$ after binder jetting, to $73.4 \%$ after infiltration and drying. After sintering at $1675{ }^{\circ} \mathrm{C}$ densities above $90 \%$ could be achieved, yielding three-point bending strengths up to $145 \mathrm{MPa}$. As a conclusion, this approach can be regarded as a promising route for overcoming the drawbacks of the binder jetting process on the way to denser, mechanically more stable sintered alumina parts.
\end{abstract}

Keywords Binder jetting $\cdot$ Aluminum oxide $\cdot$ Porosity $\cdot$ Infiltration $\cdot$ Sintering

\section{Introduction}

Additive Manufacturing (AM) of ceramics and their technological readiness evolve continuously. In their basic motivation for technological advancement, they have the potential in common with polymers and metals to fabricate complex, individual and highly innovative structures at minimum lot size while being designed for functionality [1]. For ceramics in particular, the motivation for using AM is more extensive: usually, raw materials are more expensive, molding-based restrictions are more severe and the thermal treatment and

$\triangle \mathrm{J}$. Vogt

joachim.vogt@isc.fraunhofer.de

1 Fraunhofer-Center for High-Temperature Materials and Design HTL, Gottlieb-Keim-Str. 62, 95448 Bayreuth, Germany

2 HKPC Building, 78 Tat Chee Avenue, Kowloon, Hong Kong machining processes are more time and energy consuming. Therefore, AM of ceramics offers huge economic and technological potential for the industrial fabrication of ceramic parts beyond rapid prototyping. This is becoming more and more important especially as lot numbers are decreasing and the degree of individualization is increasing continuously [2-4].

For the implementation of an economical AM-based ceramic production several issues have to be solved, like the integration in existing infrastructure, increase of reliability, holistic digitalization and reduction of part costs via an increase in productivity. As two-step manufacturing processes are mainly used in ceramic AM processes (printing and thermal consolidation), the thermal treatment cycles for debinding and densification of the parts are also essential issues for an efficient production $[3,4]$.

Up to date, several manufacturing processes are commercially used for the AM production of ceramic parts, 
partly with their own respective brand names. Among them are vat photopolymerization [e.g. stereolithography (SLA), digital light processing (DLP)/layerwise ceramic manufacturing (LCM)], extrusion-based processes [e.g. fused deposition modeling (FDM), fused filament fabrication (FFF), robocasting, ...], material jetting [e.g. drop-on demand (DOD), ink jet printing (IJP), direct ink writing (DIW), NanoParticle Jetting ${ }^{\circledR}$ (NPJ), PolyJet (PJ), ... ] and binder jetting [3-5].

Vat photopolymerization processes allow for a high resolution, highly filigree structures and a high sintered density by using light-curing slurries containing a high volume content of fine ceramic particles. Main drawbacks are a comparatively low building speed, and restrictions in wall thicknesses due to a comparatively high binder content. Extrusion-based processes are fast, require little investment cost and also allow for the use of a highly filled feedstock, yet mostly suffer from low surface quality and mechanical strength. Material jetting allows for the fabrication of dense parts at a high resolution and is particularly suited for multi-material fabrication, yet offers only limited building speed and part size length along the z-axis [4-6].

Binder jetting is of particular interest for the highthroughput industrial fabrication of ceramics on a larger scale [4]. It allows for fast production of large ceramic green parts with a high wall thickness while still enabling complex structures and overhangs [7]. The main restriction in powder-based binder jetting lies in the requirement for flowable powders, which limits the processable particle size to powders above $15 \mu \mathrm{m}$. Due to the low specific surface area, these powders show a small sinter activity, which in turn impedes the full compaction of the green parts to full density.

To mitigate these problems, several strategies have been developed, such as the use of powder mixtures [8], the granulation of fine powders with higher surface area [9], the use of slurry feedstocks [10], the use of sintering additives [11], reaction bonding [12], liquid-phase infiltration [13] and isostatic pressing [14] as well as combinations of these [7]. However, powder mixtures can impede powder flowability. Granulation of powders may increase raw material prices. The use of a slurry feedstock complicates the removal of parts from the powder bed and slows down the process. Liquid-phase infiltration with a metal melt is not expedient for oxide ceramics, as they are mostly intended for long-term use under an oxide atmosphere at high temperatures. Pressing processes are not economical and not applicable to complex structures. However, the infiltration of cured green parts with highly filled ceramic slurries containing fine particles is an easy and promising approach to increase both green packing density and sintering activity in the fabricated parts, as shown below.

\section{Experimental procedure}

AA-18 (Sumitomo Chemicals, Japan, mean particle size $20.3 \mu \mathrm{m}$ [15]) was used as main alumina powder. Initial flow ability tests (see below) and recoating tests with the M-Flex showed an insufficient flow ability for the binder jetting process (formation of slabs). A promising approach to improve the flowability of powders is to coat them with particles of significantly smaller size [16]. The attached particles increase the distance between the main particles and lower the attracting van der Waals forces. A well-known procedure is the usage of pyrogenic silica from the group of Aerosil ${ }^{\circledR}$-products by Evonik Industries AG [17]. A similar product, made of aluminum oxide, is Aeroxide ${ }^{\circledR}$ Alu C (Aeroxide ${ }^{\circledR}$ Alu C, Evonik Resource Efficiency GmbH, Germany, mean particle size $0.1 \mu \mathrm{m}$ ) [18]. Therefore, to improve the flow ability without modifying the chemical composition, the AA-18 has been modified with $0.5 \mathrm{wt} \%$ of Aeroxide ${ }^{\circledR}$ Alu C. This was done by filling portions of $1000 \mathrm{~g}$ of AA-18 and $5 \mathrm{~g}$ of Alu C into a $2000 \mathrm{~mL}$ plastic bottle, inserting them into a Turbula mixer (Turbula ${ }^{\circledR} \mathrm{T} 10 \mathrm{~B}$, WAB-Group, Switzerland) and subsequent dry mixing for $50 \mathrm{~min}$ at $80 \mathrm{rpm}$.

Particle size was measured using a Analysette 22 Nanotec from Fritsch GmbH, Germany. Dry powder samples were subjected to the embedded ultrasonic bath until an obscuration rate of about $18 \%$ was achieved. The particle size characterization was conducted using static light scattering with a wavelength of $532 \mathrm{~nm}$ and the Fraunhofer scattering model for calculation. An average of at least three converging measurements was taken.

Flow ability was evaluated using a hall flowmeter shown in Fig. 1, with a hall flowmeter funnel of $5 \mathrm{~mm}$ in diameter

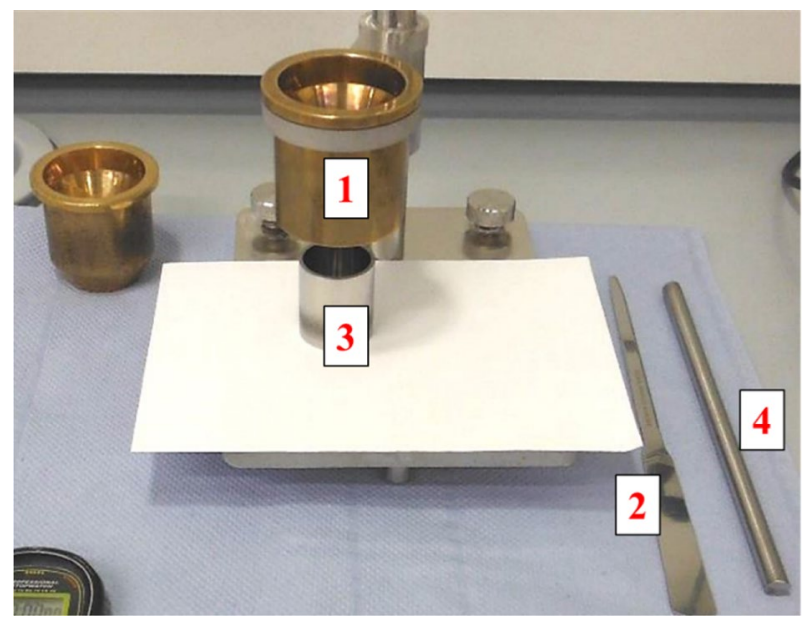

Fig. 1 Hall flowmeter setup with hall flowmeter funnel (1), scraper (2), $25 \mathrm{~cm}^{3}$ stainless steel cylinder (3) and steel rod for tapping (4) 
Table 1 Printing parameters used for the printing of the specimens showed

\begin{tabular}{lllllll}
\hline Unit & Recoater speed & Oscillator speed & $\begin{array}{l}\text { Roller } \\
\text { rotation } \\
\text { speed } \\
\text { rpm }\end{array}$ & Layer height & $\begin{array}{l}\text { Binder } \\
\text { satura- } \\
\text { tion } \\
\%\end{array}$ & Drying speed \\
& $\mathrm{mm} / \mathrm{s}$ & $\mathrm{rpm}$ & 150 & 50 & 70 & 15 \\
\hline Cuboid & 65 & 2800 & 150 & 100 & 70 & 10 \\
Bending specimens & 55 & 2800 & &
\end{tabular}

Fig. 2 Scheme of green sample infiltration for enhancement of green packing density prior to sintering

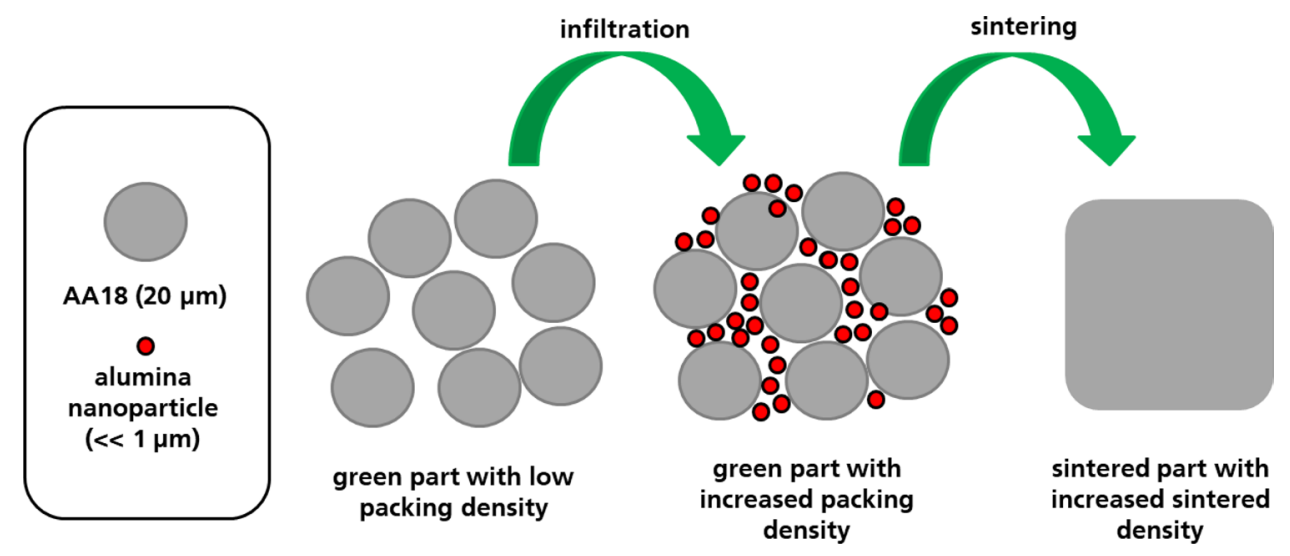

(1). The bottom of the funnel was temporarily sealed and powder was poured into the funnel until it was filled. After leveling with a scraper (2), the seal was removed and the powder flow time was noted. An average of five measurements was taken for the powder flow time. Afterwards, the powder bulk density was determined by weighing the powder mass in a stainless steel cylinder with an exact volume of $25 \mathrm{~cm}^{3}$ (3) after leveling with the scraper. The tapped density of the powder was determined via tapping on the side of the cylinder (3) with a steel rod (4) for 120 times. The reduced volume after compaction was filled up after every 30 tapping cycles with powder via the funnel, and the resulting tapped powder mass was used for calculating the tapped density. For determination of the repose angle, first, the hall funnel was filled with the respective powder, the powder was let flow through the funnel onto a paper sheet (drop height about $10 \mathrm{~cm}$ ), and images were taken from the exact front of the powder heap. The repose angle was then determined via optical evaluation of the powder heap slopes on both sides. For each value, the average of five measurements was taken.

For the fabrication of printed green parts, an M-Flex ${ }^{\circledR}$ (ExOne, USA) containing a building envelope of $400 \times 250 \times 250 \mathrm{~mm}^{3}$ has been used. Green samples were printed using the standard aqueous binder from ExOne (BA005, 5.75\% 2-butoxyethanol, 17.5 wt\% ethandiol) with the printing parameters shown in Table 1. Cuboid samples of the dimensions $8 \times 8 \times 20 \mathrm{~mm}^{3}$ were printed upright with slower printing parameters and a layer height of $50 \mu \mathrm{m}$ for the examination of the infiltration processes perpendicular to the layer planes. Three-point bending specimens of

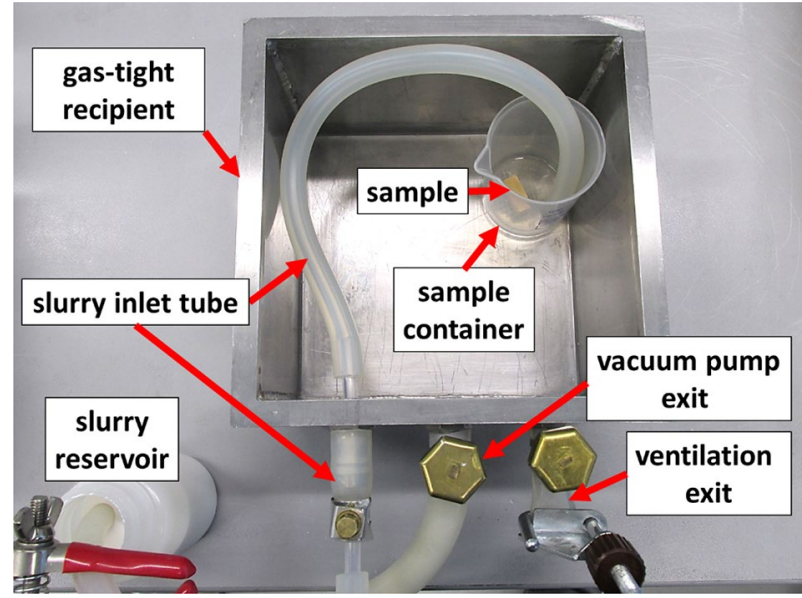

Fig. 3 Setup for the infiltration (here showing route 2). The recipient was sealed from the top with a glass plate with a sealing ring

size $4 \times 3 \times 50 \mathrm{~mm}^{3}$ were printed lying and with faster printing parameters $(100 \mu \mathrm{m}$ layer height) to investigate the applicability of the elaborated infiltration routes to fast printed parts. After the printing process, the green samples in the powder bed were cured at $180^{\circ} \mathrm{C}$ for $4 \mathrm{~h}$.

A scheme showing the green part infiltration approach mentioned in Sect. 1 is shown in Fig. 2. The infiltration procedure was carried out in a gas-tight recipient, which has three inlets (Fig. 3). One inlet can either be sealed or connected to a slurry reservoir, the second inlet is connected to a membrane vacuum pump, and the third inlet is used to vent the recipient after infiltration. When using infiltration 
route 1, the samples were placed on a grid inside a pool of slurry which covered the lower part $(\sim 20 \%)$ of the sample volume, and pressure was reduced until 10 mbar were reached. Subsequently, the pressure was kept constant for 30 min allowing the infiltration of the slurry into the sample pores to take place. When using infiltration route 2 , samples were placed in the recipient without slurry (see Fig. 3), and pressure was lowered to 10 mbar with a dwelling time of 5 min for degassing. Afterwards, the slurry was introduced at the same pressure by opening the valve of the left inlet, so that the pressure difference caused the slurry to be soaked in from the slurry reservoir (see Fig. 3). When the slurry had almost covered about the lower $20 \%$ of the sample volume, the low pressure was kept constant for $30 \mathrm{~min}$., so that the slurry infiltration into the degassed samples could take place. Printed samples before and after infiltration are shown in Fig. 4. Thus, the main difference between the two routes lies in the degassing of the samples, which was conducted during the infiltration step in procedure 1 , while being conducted before the infiltration step in procedure 2. All procedures were conducted at ambient temperature of $23^{\circ} \mathrm{C}$. Since the cuboids were used for the preliminary infiltration tests only, one cuboid was chosen for each configuration. For the application of the more elaborated parameters on bending bars, sets of at least eight bending bars were used, which were printed in the same printing run.

For the fabrication of the different infiltration slurries, two alumina powders (AKP-53 (Sumitomo Chemicals, Japan, mean particle size $0.18 \mu \mathrm{m}$ and Taimicron TM-DAR, Taimei Chemicals Co., Ltd., mean particle size $0.1 \mu \mathrm{m}$ ) were used. The powders were dispersed in deionized water (solid contents: 40, 45 and $50 \mathrm{vol} \%$ ) with $1.5 \mathrm{wt} \%$ (based on total solid content) of dispersant (Dolapix ${ }^{\circledR} \mathrm{CE}$ 64, Zschimmer $\&$ Schwarz GmbH, Germany). Dispersion was achieved by mixing the slurry in $500 \mathrm{~mL}$ PE-bottles on a roller block for $24 \mathrm{~h}$ with $3 \mathrm{~mm}$ zirconia beads. In some cases 1 droplet of 2-cotanol per $100 \mathrm{~mL}$ slurry was added to decrease the surface tension of the slurry (see Sect. 3.2).
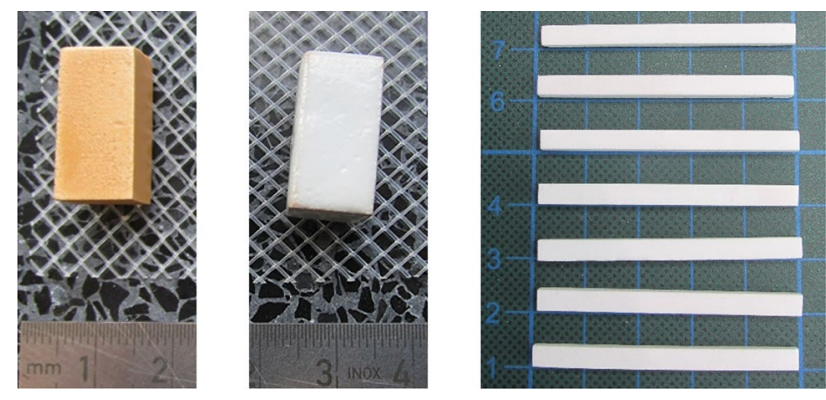

Fig. 4 3D-printed and cured cuboid sample before (left) and after slurry infiltration (middle) and analogously printed and infiltrated three-point bending bars (right)
It is known that titania acts as an effective sintering additive to alumina [20]. Therefore, some slurry formulations were modified by adding $1 \mathrm{wt} \%$ titania powder $\left(\operatorname{Kronos}^{\circledR}\right.$ 3000, Kronos International Inc., USA) with respect to the mass of alumina powder (see Sect. 3.3).

The green and infiltrated density values were determined geometrically by measuring width and length (at three points respectively) and height (at one point) in case of the cuboids and by measuring width and height (at three points) one point and length (at one point) in case of the bending bars, averaging three measurements each. After infiltration and drying, excess dried slurry was removed from the samples with a 320 grit silicon carbide grinding paper ahead of the density measurement. The error for geometrical determination of density is estimated to be about $2 \%$. The density of the sintered parts was measured via Archimedes method, with an estimated error of about $0.5 \%$.

More detailed analysis of the sintering behavior was investigated using TOMMI_last and TOM_ac. TOMMI_last and TOM_ac are two in-house developed thermooptical measurement (TOM) devices, which allow for the contactfree measurement of changes in sample dimensions (usually width and height) under defined conditions of temperature, heating rate and atmosphere. In TOMMI_last, measurements up to $1700{ }^{\circ} \mathrm{C}$ were conducted in air, as $1750{ }^{\circ} \mathrm{C}$ is the maximum service temperature due to thermal limitations of the insulation material. Measurements above $1700{ }^{\circ} \mathrm{C}$ were conducted in the graphite-based furnace TOM_ac in argon (here, air could not be used because of the graphite-based insulation and heater). The TOM measurement is based on the shadow principle and reaches a resolution of $0.3 \mu \mathrm{m}$ with high reproducibility. A sketch of TOM_ac together with the measurement principle is shown in Fig. 5. Further details concerning TOM are described in. [19]

For the general characterization of the sintering behavior in the TOM devices and the influence of the respective additives, cylindrical samples of the approximate dimension $10 \mathrm{~mm}$ diameter, $10 \mathrm{~mm}$ height were used.

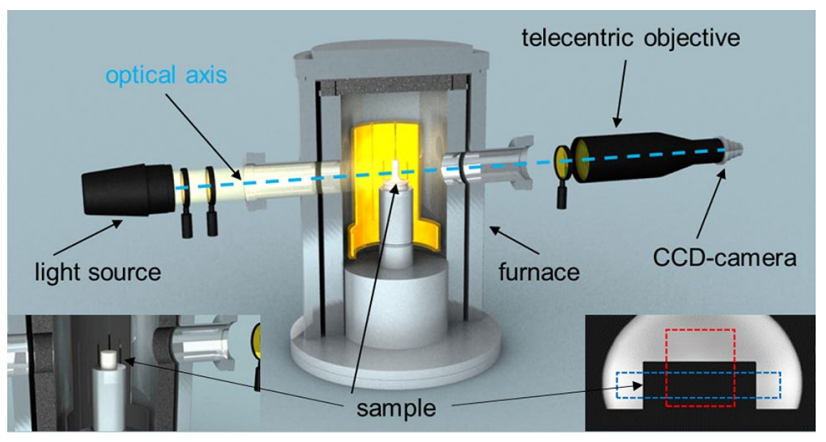

Fig. 5 Scheme of the measurement principle of TOM_ac. For more details, reference is made to [19] 
The cylinders were prepared by dispersing the respective amounts of AA18 powder, AluC and, if applicable, Kronos 3000 titania powder in deionized water (solid content of 30 vol\%) using Dolapix ${ }^{\circledR}$ CE 64 (Zschimmer \& Schwarz $\mathrm{GmbH}$, Germany) as dispersant. The slurry was subsequently freeze-dried (Alpha 1-4, Martin Christ Gefriertrocknungsanlagen $\mathrm{GmbH}$, drying temperature $-56^{\circ} \mathrm{C}$, $10 \mathrm{mbar}$ ) and the resulting powder was cold isostatically pressed (KIP 500 E, Paul-Otto Weber $\mathrm{GmbH}$ ) at 750 bars to cylinders of the above-mentioned dimensions.

The general sintering of the samples was performed in an oxidic furnace (Nabertherm HT04-1750 ${ }^{\circ} \mathrm{C}$ ). The heating rate was $2 \mathrm{~K} / \mathrm{min}$., the sintering temperature was $1675{ }^{\circ} \mathrm{C}$ with a dwelling time of $5 \mathrm{~h}$ (cuboids) and $10 \mathrm{~h}$ (three-point bending bars), respectively.

For microscopical analysis, samples were cut with a precision saw (Accutom 5, Struers Inc., USA), embedded in resin (Buehler EpoHeat CLR resin and hardener), ground and polished (AutoMet 300, Struers Inc., USA). The samples were then analyzed with an optical microscope (DM 4000 M, Leica Microsystems) using a highresolution camera (DFC 295, Leica Microsystems). For the preparation of a cross-section image, six images were created along the sample latitude in bright field illumination using a $5 \times$ magnification. Afterwards, the respective microscopic images were merged together using the Leica Application Suite software.

Three-point bending tests were performed using a universal testing machine (Inspekt 100 Table, Hegewald \& Peschke), corresponding to DIN EN ISO 853-1, configuration B (support distance $40 \mathrm{~mm}$ ) with a traverse speed of $0.025 \mathrm{~mm} / \mathrm{s}$.

\section{Results and discussion}

\subsection{Flow ability and sintering behavior of the raw materials}

AA18 consists of $\alpha$-alumina single crystals of precisely controlled particle size distribution and almost-spherical polyhedral shape. A SEM picture of the primary particles (taken from [15]) and the measured particle size distribution are shown in Fig. 6.

Due to its mean particle size of about $20 \mu \mathrm{m}$ and its narrow particle size distribution, AA18 should be suitable for powder bed processes. However, a standard evaluation with respect to its flow ability (repose angle, funnel flow time, bulk and tapped density are given in Table 2) showed relatively long flow times and high repose angles. Furthermore,
Fig. 6 Left: SEM picture of AA18 single crystals, taken from [15]. Right: Particle size distribution (red curve) of AA18 determined via static light scattering
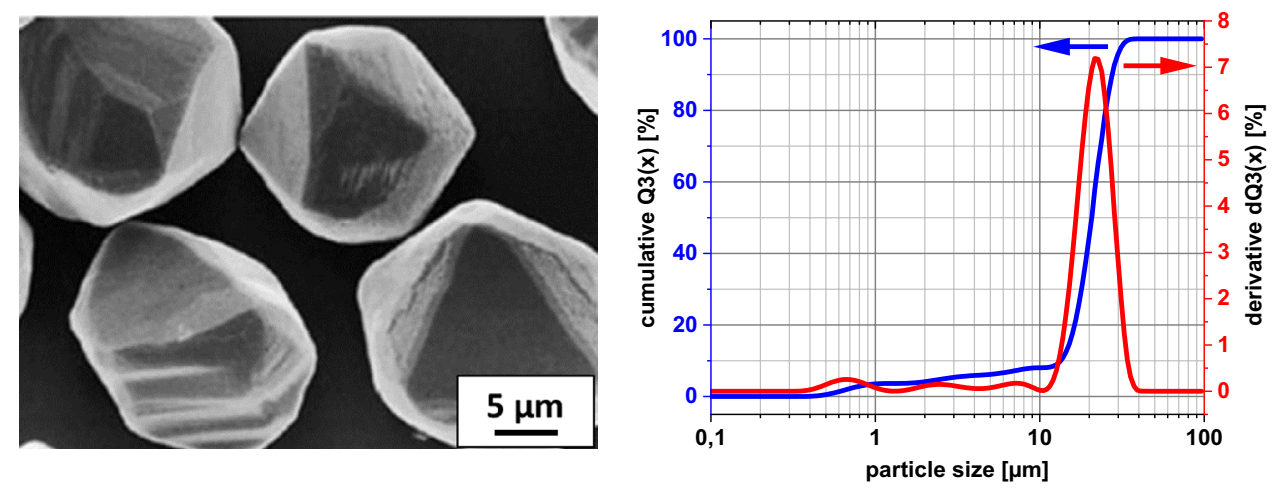

Table 2 Particle size and flow ability parameters for AA18 with and without AluC measured at the HTL and data provided by the supplier

\begin{tabular}{|c|c|c|c|c|c|c|c|}
\hline \multirow[b]{3}{*}{ AA18 } & \multirow{3}{*}{$\begin{array}{l}\mathrm{d}_{50} \text { value } \\
\frac{\mu \mathrm{m}}{20.5}\end{array}$} & \multirow{3}{*}{$\begin{array}{l}\text { Repose angle } \\
\text { ○ } \\
36.5\end{array}$} & \multirow{3}{*}{$\begin{array}{l}\text { Flow time } \\
\text { s } \\
29.4\end{array}$} & \multirow{2}{*}{\multicolumn{2}{|c|}{$\begin{array}{l}\text { Bulk density/(pack- } \\
\left.\text { ing density }{ }^{\mathrm{b}}\right) \\
\mathrm{g} / \mathrm{cm}^{3} /(\%)\end{array}$}} & \multirow{2}{*}{\multicolumn{2}{|c|}{$\begin{array}{l}\text { Tapped density/ } \\
\text { (packing } \\
\text { density }^{\mathrm{b}} \text { ) } \\
\mathrm{g} / \mathrm{cm}^{3} /(\%)\end{array}$}} \\
\hline & & & & & & & \\
\hline & & & & 1.98 & $49.5 \%$ & 2.52 & $63.0 \%$ \\
\hline AA18 + AluC & 20.5 & 33.5 & 24.4 & 2.01 & $50.3 \%$ & 2.50 & $62.6 \%$ \\
\hline AA18 supplier ${ }^{\mathrm{a}}$ & 20.3 & - & - & 2.00 & $50.1 \%$ & 2.40 & $60.1 \%$ \\
\hline
\end{tabular}

For comparison, the properties of SS420 $(30 \mu \mathrm{m})$ stainless steel powder material from ExOne were measured to be: repose angle $29.6^{\circ}$, flow time $27.1 \mathrm{~s}$, bulk packing density $53.4 \%$, tapped packing density $61.2 \%$.

${ }^{\text {a } I n f o r m a t i o n ~ g i v e n ~ b y ~ t h e ~ s u p p l i e r ~ i n ~[15] ~}$

${ }^{\mathrm{b}}$ Based on an absolute powder density of $3.995 \mathrm{~g} / \mathrm{cm}^{3}$ [21] 
recoating tests in the M-Flex printer showed the formation of platelets and gaps due to insufficient powder flow. Despite the poor flow properties, the bulk and tapped density are comparatively high. The effects of the coating with the nanoscale alumina AluC can also be seen in Table 2. The flowability characteristics improved only slightly, but printing tests in the 3D printer showed a significant improvement. Specimen of different geometry could be printed according to the printing parameters given in Table 1, whereas printing of AA18 only was not possible even after varying different printing parameters.

Besides the printing properties the densification behavior of the powders during sintering is of utmost importance for binder jetting. Figure 7 shows shrinkage curves of AA18 for different thermal treatment cycles and additives. The diagram shows the relative width of the samples as a function of time during the respective thermal treatment cycle.

After a slight dimensional increase while heating due to thermal expansion, the start of the densification is evident by a notable width reduction. After the holding time, the samples shrink due to cooling. The shrinkage is determined via the reduction of relative width between the heating and the cooling stage at the same temperature in a rel. width vs. temperature plot (not shown here). Additionally, curves with respect to the effect of AluC (orange) and the addition of $\mathrm{TiO}_{2}$ (grey) as sintering aid are included.

As can be seen in Fig. 7, the sintering activity of all samples is low. At standard sintering conditions for alumina $\left(1500-1600{ }^{\circ} \mathrm{C}\right.$ ), a negligible shrinkage of only $0.1 \%$ and $0.3 \%$ for the sample with and without AluC, respectively,

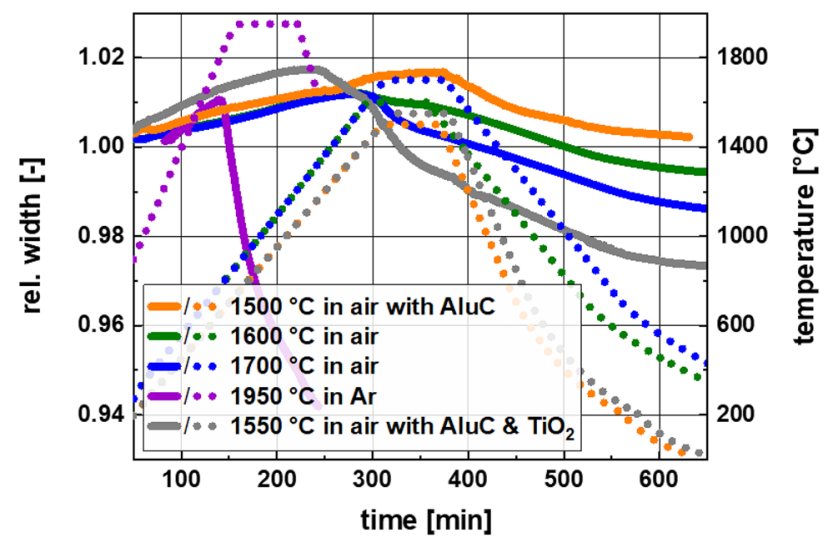

Fig. 7 Sintering curves of alumina samples with different maximum temperatures and compositions. The solid lines display the relative sample width as a function of time, the dotted lines display the temperature as a function of time. At temperatures $\leq 1700{ }^{\circ} \mathrm{C}$, a heating rate of $5 \mathrm{~K} / \mathrm{min}$. was used. At $1950{ }^{\circ} \mathrm{C}$, a heating and cooling rate of $10 \mathrm{~K} / \mathrm{min}$. was used. Below $800{ }^{\circ} \mathrm{C}$, the cooling was done passively. The relative green densities of the samples were: $1500{ }^{\circ} \mathrm{C}$ in air with AluC: $60.5 \% ; 1600{ }^{\circ} \mathrm{C}$ in air: $67.3 \% ; 1700{ }^{\circ} \mathrm{C}$ in air: $67.9 \% ; 1950{ }^{\circ} \mathrm{C}$ in $\mathrm{Ar}: 66 \%: 1550^{\circ} \mathrm{C}$ in air with $\mathrm{AluC} \& \mathrm{TiO}_{2}: 61.1 \%$ could be achieved. This can be attributed to the small surface area of the AA18 particles. The effect of the AluC particles is also rather negligible considering the small difference in sintering temperature. The amount of fine particles is too small, and they do not increase the number of particle contacts, which would be a necessity for improving the sintering process.

One approach to enhance the densification is to increase the sintering temperature. A slightly increased shrinkage of $1.1 \%$ could be achieved by sintering at $1700{ }^{\circ} \mathrm{C}$. However, densification is still far below being acceptable. Therefore, a graphite furnace (TOM_ac) was used to sinter at $1950{ }^{\circ} \mathrm{C}$ under inert (argon) atmosphere. In this case, a final density of $3.38 \mathrm{~g} / \mathrm{cm}^{3}$ (85.6\% of theoretical density, measured via Archimedes method) could be achieved with a shrinkage of $5.7 \%$. This is a significant increase, but still insufficient for mechanically stable ceramics. Furthermore, it is important to note that this value was achieved with cold isostatically pressed samples, which exhibit a higher green density and more particle contacts than samples fabricated in a powder layering process such as binder jetting. Therefore, in case of binder jetting, even more thermal energy for sintering would be needed. A further enhancement of the density by increasing the sintering temperature would also be difficult with respect to industrial processing, as the melting temperature of pure alumina is $2050{ }^{\circ} \mathrm{C}$ [16], and large industrial kilns are less accurately controlled.

For this reason, an alternative approach to increase the density and sintering activity of samples fabricated from AA18 was needed, especially when performing binder jetting. Therefore, the above-mentioned approach was chosen, the infiltration of green samples after printing and curing with particles of smaller particle size ahead of the heat treatment process (see Fig. 2). In parallel, the addition of $\mathrm{TiO}_{2}$ was considered (see Sect. 2). $\mathrm{TiO}_{2}$ reduces the onset of sintering and facilitates densification as clearly shown in Fig. 7, where a significant increase in shrinkage was observed. This effect could also be beneficial for achieving materials of lower porosity.

\subsection{Infiltration route 1}

The resulting infiltrated densities after the application of infiltration route 1 on 3D-printed and cured green samples with slurries of different particle sizes and volume contents are shown in Fig. 8. The relative green density values varied between $47.8 \%$ and $49.7 \%$ because of deviations in the printing process.

It can be seen that, without infiltration, the maximally achieved sintered density is about $51.5 \%$, which is an increase in density of only $3.3 \%$. This indicates the need for a strategy to clearly enhance sintered density. Using infiltration route 1 and different slurry compositions, the green 


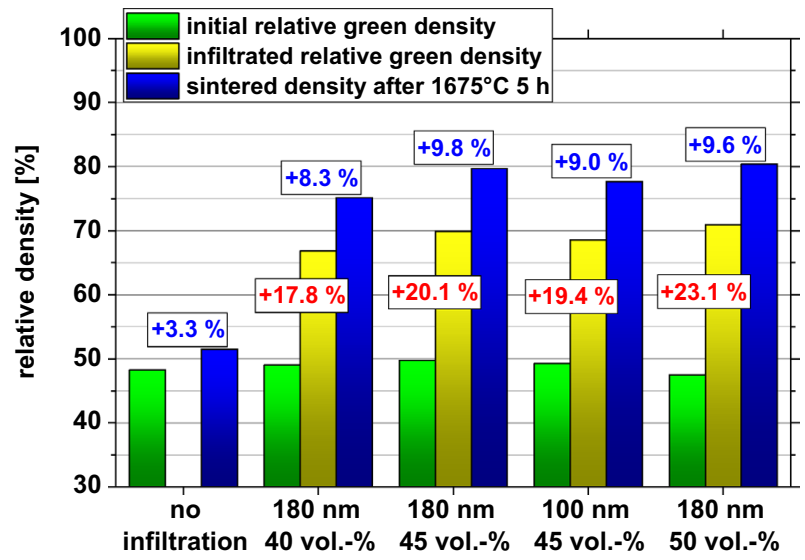

Fig. 8 Initial green densities (green), green densities after slurry infiltration route 1 (yellow) and sintered densities (blue) after sintering at $1675^{\circ} \mathrm{C}$ for $5 \mathrm{~h}$. The increase in green density via infiltration is highlighted in red, the increase in density via sintering is highlighted in blue

density of the samples could be significantly increased by $17.8-20.1 \%$ to up to $70.9 \%$. The densities after sintering at $1675^{\circ} \mathrm{C}$ for $5 \mathrm{~h}$ reached up to $80.4 \%$. When comparing the results, it can be seen that a slightly higher gain in green density could be achieved using a slurry containing either $45 \mathrm{vol} \%$ or $50 \mathrm{vol} \%$ of particles with a mean particle size of $180 \mathrm{~nm}$.

The resulting microstructure of the respective samples is shown in Fig. 9. It can be seen that all samples exhibit areas with a lower overall density, indicating that no complete and

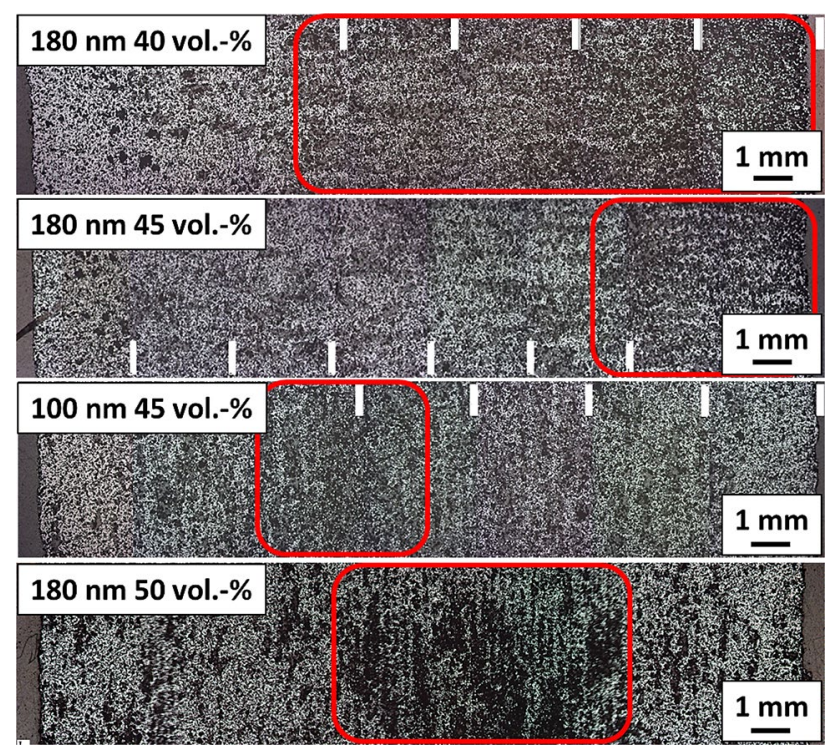

Fig. 9 Mounted microscopic images of sintered cuboid AA18-samples (3D-printed and infiltrated with slurries with different solid content and particle size before sintering). Sample regions with lower density are highlighted in red homogeneous infiltration took place. In the case of the highest concentrated slurry at $50 \mathrm{vol} \%$, a large area with significantly lower density can be seen at the center of the sample, while in the case of a lower concentration (40 vol\%), about two-thirds of the sample show a lower density. The sample prepared with the slurry containing $45 \mathrm{vol} \%$ of particles at $180 \mathrm{~nm}$ size showed the best compromise between achieved sintered density and infiltration depth. The use of the same content of $100 \mathrm{~nm}$-sized alumina powder for infiltration showed no significant improvement in density and homogeneity. Since the density values of the $45 \mathrm{vol} \%$ and $50 \mathrm{vol} \%$ slurry are not differing significantly (see above), but a higher degree of homogeneity in the sample cross-section could be observed, a slurry with $45 \mathrm{vol} \%$ of $180 \mathrm{~nm}$-sized powder was chosen for the following improved infiltration setup.

\subsection{Infiltration route 2}

In infiltration route 2, samples were degassed prior to slurry infiltration with a slurry containing $45 \mathrm{vol} \%$ of $180 \mathrm{~nm}$ alumina (designated "original" in the following). Furthermore, slurries containing 2-octanol as a wetting agent and slurries additionally containing $1 \mathrm{wt} \%$ titania as a sintering additive have been investigated. The results are shown in Fig. 10. The relative green density values of the bending bars after printing varied between $46.7 \%$ and $49.5 \%$ because of deviations in the printing process.

It can be seen that by degassing the samples before the slurry infiltration, while using the same slurry (i.e. 45 vol\% of $180 \mathrm{~nm}$-sized alumina particles), a higher increase in packing density could be achieved $(+26.2 \%$ vs. $+20.1 \%$ via route 1$)$. The increase in packing density was only slightly

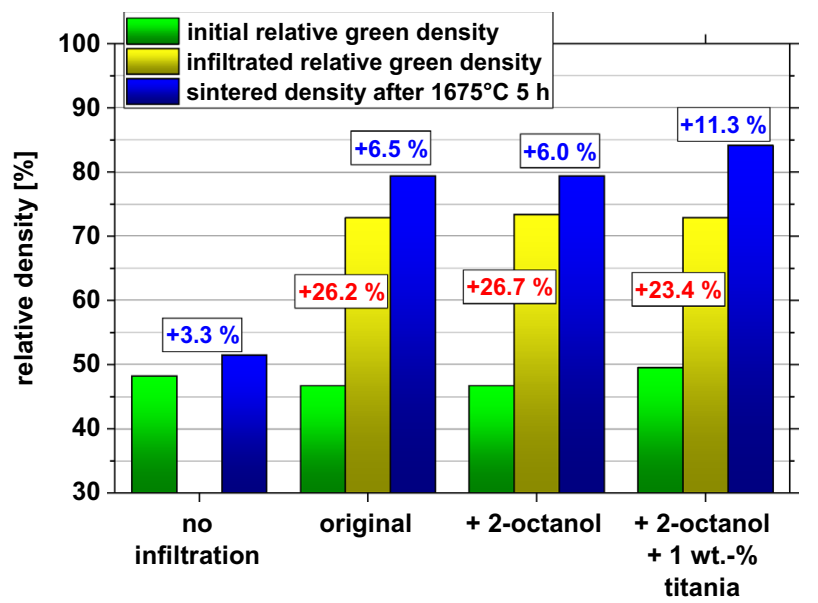

Fig. 10 Initial green densities (green), green densities after slurry infiltration route 2 (yellow) and sintered densities (blue) after sintering at $1675^{\circ} \mathrm{C}$ for $5 \mathrm{~h}$. The increase in green density via infiltration is highlighted in red, the increase in density via sintering is highlighted in blue 
higher with $+26.7 \%$ giving a density of $73.4 \%$ upon use of 2-octanol as a wetting agent, so the promoting influence of 2-octanol during infiltration is negligible when pre-degassed samples are treated. When comparing these two samples, the sintered density is also the same being $79.4 \%$.

The increase in packing density upon infiltration with the titania-containing slurry was comparatively lower $(+23.4 \%)$, because the initial green density of the infiltrated sample with $49.5 \%$ was slightly higher. Nevertheless, the relative increase in density during sintering was almost doubled $(+11.3 \%)$ when compared to the other slurries due to the effect of the titania serving as a sintering additive. The resulting sintered density reached $84.2 \%$, which is about $24 \%$ higher than in case of the sample without slurry.

In Fig. 11, mounted microscopic images of a cross-cut of the samples are shown. It can be seen that the full potential in sample infiltration is still not fully exploited. Although the density of the samples is higher than in the case of infiltration route 1 , areas with lower density still exist. Therefore, significantly higher densities can be expected if full infiltration is achieved.

When comparing the sintered densities, it is still unclear why the much higher relative densities in the infiltrated state of the samples "original" and "+2-octanol" did not result in a substantially higher sintered density when compared to the results of infiltration route 1 . One explanation could be that the irregular distribution of infiltrated particles over the sample cross-section resulted in internal stresses during sintering, which prevented further densification. Therefore, a more uniform particle distribution by full infiltration should be aimed at to achieve a higher sintered density here.

\subsection{Infiltration and sintering of bending specimens and mechanical testing}

The improved infiltration procedure (no. 2) and the selected slurry formulation (45 vol\% $180 \mathrm{~nm}+2$-octanol; + $1 \mathrm{wt} \%$ titania, if applicable) was applied to 3D-printed, green bending bar specimen to quantify the influence of the increase in sintered density on the mechanical strength. Since the influence of 2-octanol can be either positive or negligible, it was also used in these slurries. The infiltration of the green bending bars was conducted with the bending bars lying in-plane.

The results of the infiltration of the green bending bars concerning density are shown in Fig. 12. The green density values varied by $\pm 2.7 \%$. It can be seen that non-infiltrated samples showed only a small increase in density during sintering. Despite the higher dwelling time of $10 \mathrm{~h}$, relative sintered density was only $53.3 \%$. Upon infiltration of the green specimen with infiltration route 2 using slurries containing $45 \mathrm{vol} \%$ of AKP53 and 2-octanol (with $1 \mathrm{wt} \%$ titania), an increase in relative green density of $+27.2 \%$ and $+29.2 \%$ could be achieved, resulting in green densities of $72.8 \%$ and $74.6 \%$, respectively, which is in the same range as described in Sect. 3.3 for the cuboids. The rise in density during sintering was $+15.6 \%$ and $+16.6 \%$, respectively, resulting in relative sintered densities of $88.3 \%$ and 91.2\%. When compared to the cuboids in Sect. 3.3, the higher increase in density of both series can be attributed

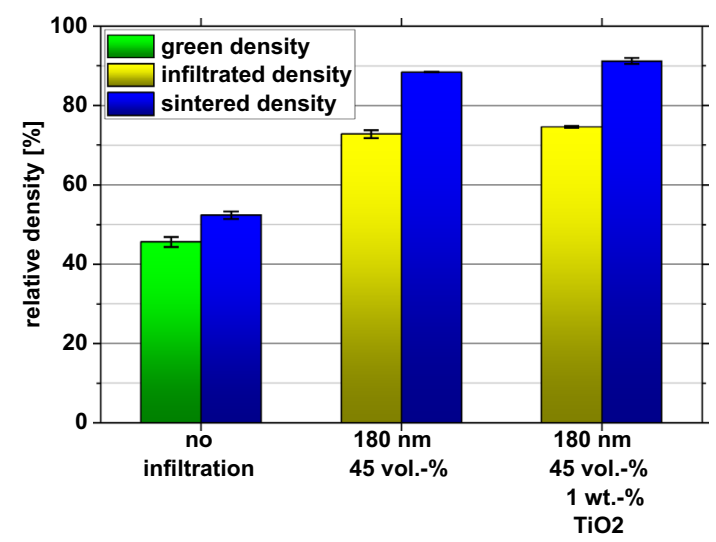

Fig. 12 Relative densities of green (no infiltration, green bar) and infiltrated three-point bending specimen (yellow bars) and sintered densities after $1675^{\circ} \mathrm{C}$ for $10 \mathrm{~h}$ (blue bars)
Fig. 11 Mounted microscopic images of cuboid AA18-samples (3D-printed and infiltrated with slurries with a solid content of $45 \mathrm{vol} \%$ including 2-octanol and titania as additives before sintering). The infiltration took place from the left to the right

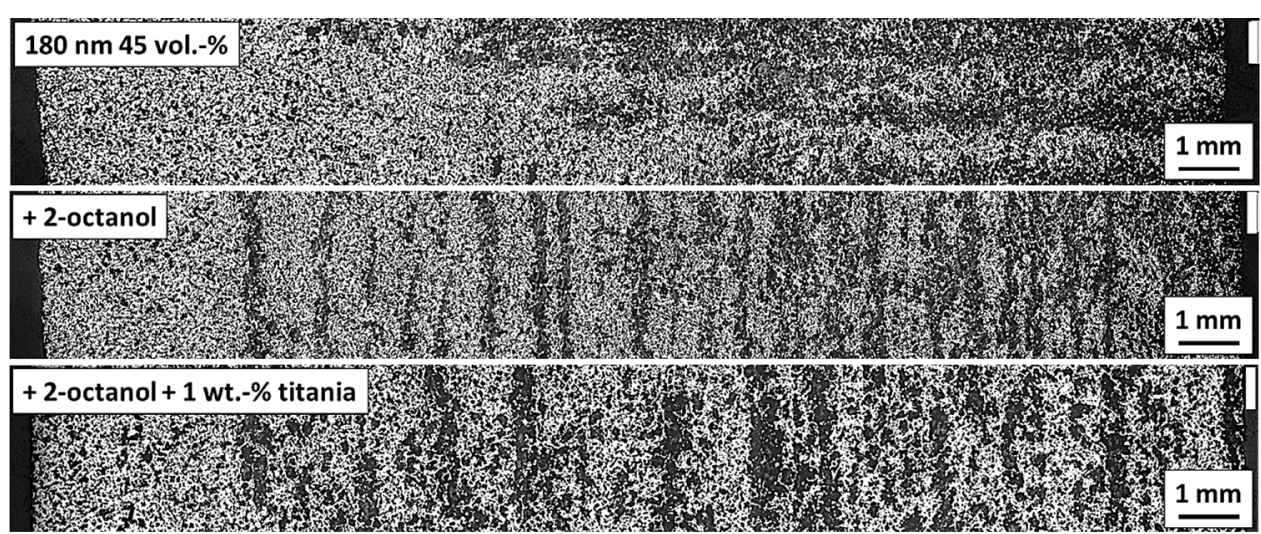


to the higher dwelling time during sintering. Furthermore, the infiltration might be slightly more uniform, as the sample cross-section was lower. This is to be cleared by future microstructural analysis.

Despite this, the influence of titania on sintered density is not significant here. One possible explanation for this could be that at sintering times above $5 \mathrm{~h}$ the effect of titania in promoting the sintering process is not significant anymore, because the titania particles mainly reduce the onset of sintering due to melt formation. Another explanation, which could also overlap with the effect mentioned before, is that titania may cause internal stresses which are caused by the increased sintering rates, which may result in microcracks impeding further densification.

Figure 13 depicts the results from the three-point bending tests. It can be seen that, due to the above-mentioned low sintering activity of the AA18, only little compaction took place in case of the non-infiltrated samples, resulting in a bending strength of only about $6.2 \pm 0.6 \mathrm{MPa}$. The increase in sintered density via infiltration has a direct impact on the strength of the specimen, resulting in a three-point bending strength of about $125.4 \pm 14.6 \mathrm{MPa}$ with the alumina infiltration slurry without titania, which is about a 20 -fold increase when compared to non-infiltrated samples. Upon addition of $1 \mathrm{wt} \%$ titania to the slurry, the bending strength could be even further increased by about $15.8 \%$ to about 145.2 $\pm 18.3 \mathrm{MPa}$. Hence, although sintered densities of samples infiltrated with the titania-doped alumina slurry are only slightly higher than in case of the non-doped slurry, a significant positive effect of titania on the mechanical stability can be observed. Despite the above-mentioned possibility to cause microcracks due to high sintering rates, the increased mechanical strength could be a result of an overall

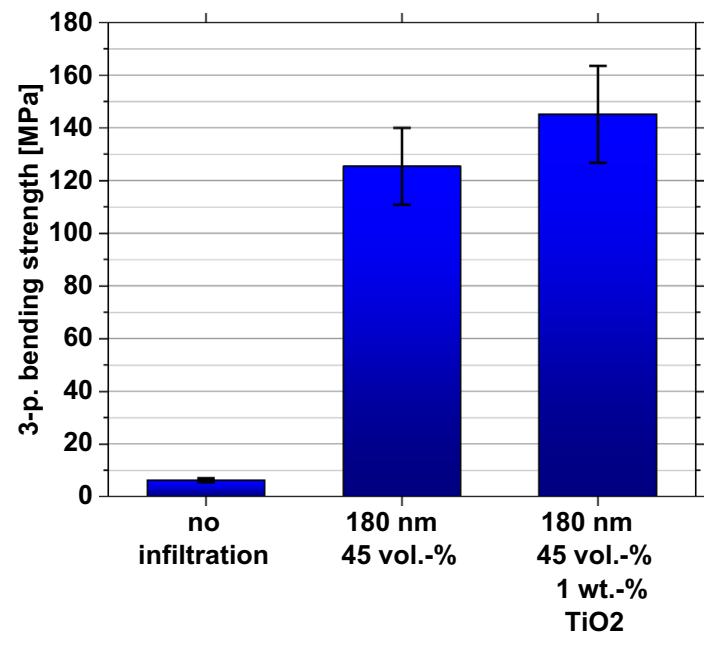

Fig. 13 Three-point bending strength values of non-infiltrated and infiltrated bending bars, which were sintered at $1675{ }^{\circ} \mathrm{C}$ for $10 \mathrm{~h}$ $(\mathrm{n} \geq 8)$ stronger intergranular bonding caused by the intensified sintering activity via titania doping. To give a clear explanation to this, microstructural characterization via SEM in future investigations would be necessary.

Compared to the bending strength of dense alumina with 400-450 MPa [21], the achieved values are about one third of the monolithic value. The difference to the latter can be explained with the lower sintered densities, lager grain sizes and an inhomogeneous distribution of the smaller particles across the sample cross-section. Therefore, further optimization of the infiltration slurries and procedures promise to yield higher sintered densities and three-point bending strengths. Yet, reaching full density via the described infiltration approach is unlikely, as the performance of infiltration processes are known to be limited by open porous infiltration pathways, infiltration pathway lengths and the distribution of the infiltrating species. Furthermore, the presence of a volume fraction of coarse particles $>45 \mathrm{vol} \%$ with interparticle contacts may impede structural rearrangement for full densification. Nevertheless, densities beyond $90 \%$ are likely to be achievable.

\section{Conclusion}

Using nanoparticulate alumina Aeroxide ${ }^{\circledR}$ AluC as an additive, polyhedral $20 \mu \mathrm{m}$-sized alumina powder AA18 was rendered suitable for the fabrication of green parts via binder jetting. The sintering behavior of the feedstocks was analyzed using thermooptical measurement devices showing insufficient densification of non-infiltrated samples even at $1950{ }^{\circ} \mathrm{C}$ but a beneficial influence of titania as sintering additive. Based on this, 3D-printed green samples were infiltrated with highly loaded ceramics slurries of different particle sizes and concentrations. It was shown that the degassing of the samples prior to infiltration has a positive effect on the infiltration of the samples. The green densities of cuboid samples of $8 \times 8 \times 20 \mathrm{~mm}^{3}$ size could be increased by up to $26.7 \%$, yielding green densities up to $73.4 \%$ and sintered densities up to $79.4 \%$. When using an additional $1 \mathrm{wt} \%$ titania in the slurries as a sintering additive, sintered densities could be further raised up to $84.2 \%$. However, the cross-sections of the samples still exhibit an inhomogeneous microstructure, indicating incomplete infiltration of the former.

Green-state slurry infiltration of pre-degassed three-point bending bars of $4 \times 3 \times 50 \mathrm{~mm}^{3}$ size and sintering at $1675^{\circ} \mathrm{C}$ for $10 \mathrm{~h}$ showed a further increase in relative sintered density up to $91.2 \%$, resulting in three-point bending strengths up to about $145 \mathrm{MPa}$. This is a 20- to 23-fold increase when compared to non-infiltrated sintered bending bars. The further increase in sintered density can be attributed mainly to the extended dwelling time during sintering. 
To substantiate the above-mentioned observations, more statistical analysis and further microscopical analysis is needed. Further optimization of the infiltration procedure (e.g. by adaptions in slurry handling), of the slurry formulation and of the content of sintering additives (titania, magnesia) should also be part of future work. This has the potential to yield higher green and sintered densities, resulting in higher bending strengths, respectively. Also, the possibility to further enhance the density by adapting the thermal processing has to be examined.

Additionally, it should be noted, that full densification is hampered by a high amount of particle contacts of coarse particles as well as the limits of open porous pathways, pathway lengths and the homogeneous distribution of the infiltrating particles. Therefore, applications in the field of high-end technical ceramics demanding full densifications are unlikely to be accessible in this route.

However, the infiltration of cured green samples offers an easy-to-adapt and promising approach to increase the sintered density of oxide ceramic parts fabricated via binder jetting to beyond $90 \%$.

Acknowledgements The authors want to thank their colleagues Waldemar Walschewski for his support regarding the printing of the samples and Wolfgang Bernstein for conducting the three-point bending tests.

Funding Open Access funding enabled and organized by Projekt DEAL.

Availability of data and material The datasets generated during and/or analyzed during the current study are available from the corresponding author on reasonable request.

Code availability Not applicable.

\section{Declarations}

Conflict of interest The authors have no conflicts of interest to declare. All co-authors have seen and agree with the contents of the manuscript and there is no financial interest to report. We certify that the submission is original work and is not under review at any other publication.

Ethical approval Not applicable.

Informed consent Not applicable

Open Access This article is licensed under a Creative Commons Attribution 4.0 International License, which permits use, sharing, adaptation, distribution and reproduction in any medium or format, as long as you give appropriate credit to the original author(s) and the source, provide a link to the Creative Commons licence, and indicate if changes were made. The images or other third party material in this article are included in the article's Creative Commons licence, unless indicated otherwise in a credit line to the material. If material is not included in the article's Creative Commons licence and your intended use is not permitted by statutory regulation or exceeds the permitted use, you will need to obtain permission directly from the copyright holder. To view a copy of this licence, visit http://creativecommons.org/licenses/by/4.0/.

\section{References}

1. Ngo TD, Kashani A, Imbalzano G, Nguyen KTQ, Hui D (2018) Additive manufacturing (3D printing): a review of materials, methods, applications and challenges. Compos B Eng 143:172196. https://doi.org/10.1016/j.compositesb.2018.02.012

2. Castro e Costa E, Duarte JP, Bártolo P (2017) A review of additive manufacturing for ceramic production. Rapid Prototyp J 23(5):954-963. https://doi.org/10.1108/RPJ-09-2015-0128

3. Lakhdar Y, Tuck C, Binner J, Terry A, Goodridge R (2021) Additive manufacturing of advanced ceramic materials. Prog Mater Sci 116:100736. https://doi.org/10.1016/j.pmatsci.2020. 100736

4. Wang JC, Dommati H, Hsieh SJ (2019) Review of additive manufacturing methods for high-performance ceramic materials. Int J Adv Manuf Technol 103:2627-2647. https://doi.org/ 10.1007/s00170-019-03669-3

5. Chen Z, Li Z, Li J, Liu C, Lao C, Fu Y, Liu C, Li Y, Wang P, He Y (2019) 3D printing of ceramics: a review. J Eur Ceram Soc 39:661-687. https://doi.org/10.1016/j.jeurceramsoc.2018. 11.013

6. Jang S, Park S, Bae CJ (2020) Development of ceramic additive manufacturing: process and materials technology. Biomed Eng Lett 10:493-503. https://doi.org/10.1007/s13534-020-00175-4

7. Du W, Ren X, Pei Z, Ma C (2020) Ceramic binder jetting additive manufacturing: a literature review on density. J Manuf Sci Eng 142:040801-1-40819. https://doi.org/10.1115/1.4046248

8. Du W, Ren X, Chen Y, Ma C, Radovic M, Pei Z (2018) Model guided mixing of ceramic powders with graded particle sizes in binder jetting additive manufacturing. In: ASME 2018 13th international manufacturing science and engineering conference June 18-22, 2018 College Station, Texas, USA. https://doi.org/ 10.1115/MSEC2018-6651

9. Miao G, Du W, Moghadasi M, Pei Z, Maa C (2020) Ceramic binder jetting additive manufacturing: effects of granulation on properties of feedstock powder and printed and sintered parts. Addit Manuf. https://doi.org/10.1016/j.addma.2020.101542

10. Zocca A, Lima P, Günster J (2017) LSD-based 3D printing of alumina ceramics. J Ceram Sci Technol 08(01):141-148. https:// doi.org/10.4416/JCST2016-00103

11. Fielding GA, Bandyopadhyay A, Bose S (2012) Effects of silica and zinc oxide doping on mechanical and biological properties of $3 \mathrm{D}$ printed tricalcium phosphate tissue engineering scaffolds. Dent Mater J 28(2):113-122. https://doi.org/10.1016/j.dental. 2011.09.010

12. Solis DM, Silva AV, Volpato N, Berti LF (2019) Reaction-bonding of aluminum oxide processed by binder jetting. J Manuf Process 41:267-272. https://doi.org/10.1016/j.jmapro.2019.04. 008

13. Cramer CL, Nandwana P, Lowden RA, Elliott AM (2019) Infiltration studies of additive manufacture of WC with Co using binder jetting and pressureless melt method. Addit Manuf 28:333-343. https://doi.org/10.1016/j.addma.2019.04.009

14. Sun W, Dcosta DJ, Lin F, El-Raghy T (2002) Freeform fabrication of $\mathrm{Ti}_{3} \mathrm{SiC}_{2}$ powder-based structures: Part I-Integrated fabrication process. J Mater Process Technol 127(3):343-351. https://doi.org/10.1016/S0924-0136(02)00284-4

15. Sumitomo Chemical Product Databook Alumina (2016) https:// www.sumikamaterials.com/wp-content/uploads/2016/10/Produ ct-Databook-Alumina.pdf. Accessed 31 Mar 2021

16. Eber M (2004) Wirksamkeit und Leistungsfähigkeit von nanoskaligen Fließregulierungsmitteln, Dissertation, University of Würzburg. urn:nbn:de:bvb:20-opus-9026

17. Evonic Industries Product Datasheet Aerosil ${ }^{\circledR} 300$ (2019) https://products-re.evonik.com/www2/uploads/productfinder/ 
AEROSIL-300-EN.pdfxd_co_f $=$ YjBjOTg5YWQtOGI3Ni00 MTNiLWIzZDMtOTM5ZDY3NGUwZDZk. Accessed 31 Mar 2021

18. Evonik Resource Efficiency $\mathrm{GmbH}$, Product information AEROXIDE $^{\circledR}$ Alu C (2019) https://products-re.evonik.com/ www2/uploads/productfinder/AEROXIDE-Alu-C-EN.pdf. Accessed 31 Mar 2021

19. Baber J, Klimera A, Raether F (2007) In situ measurement of dimensional changes and temperature fields during sintering with a novel thermooptical measuring device. J Eur Ceram Soc 27(2-3):701-705. https://doi.org/10.1016/j.jeurceramsoc.2006. 04.043
20. Lahiri S, Sinhamahapatra S, Tripathi HS, Dana K (2016) Rationalizing the role of magnesia and titania on sintering of $\alpha$-alumina. Ceram Int 42:15405-15413. https://doi.org/10. 1016/j.ceramint.2016.06.189

21. Salmang H, Scholze H (2007) Keramik. Springer, Berlin Heidelberg New York

Publisher's Note Springer Nature remains neutral with regard to jurisdictional claims in published maps and institutional affiliations. 